\title{
Configurações
}

Revista de sociologia

\section{Reflexões sobre a implementação de um programa de intervenção psicoeducativa com mulheres ciganas portuguesas}

Reflections on the implementation of a programme of psychoeducational intervention with Portuguese Roma women.

Réflexion sur la mise en oeuvre d'un programme d'intervention psychoéducative avec des femmes Roms portugaises.

Sofia Neves, Ariana Correia e Paula Allen

\section{OpenEdition}

\section{Journals}

\section{Edição electrónica}

URL: http://journals.openedition.org/configuracoes/3695

DOI: $10.4000 /$ configuracoes.3695

ISSN: 2182-7419

\section{Editora}

Centro de Investigação em Ciências Sociais

Edição impressa

Paginação: 122-139

ISSN: 1646-5075

\section{Refêrencia eletrónica}

Sofia Neves, Ariana Correia e Paula Allen, «Reflexões sobre a implementação de um programa de intervenção psicoeducativa com mulheres ciganas portuguesas », Configurações [Online], 18| 2016, posto online no dia 30 dezembro 2016, consultado o 01 maio 2019. URL : http://

journals.openedition.org/configuracoes/3695; DOI : 10.4000/configuracoes.3695 
Neves, Sofia; Correia, Ariana; Allen, Paula - Reflexões sobre a implementação de um programa de intervenção psicoeducativa com mulheres ciganas portuguesas Configurações, vol. 18, 2016, pp. 122-139

\title{
Reflexões sobre a implementação de um programa de interven- ção psicoeducativa com mulheres ciganas portuguesas
}

\author{
SOFIA NEVES* \\ Instituto Universitário da Maia (ISMAI) \\ ARIANA CORREIA** \\ Universidade do Porto \\ PAULA ALLEN ${ }^{* * *}$ \\ Associação Plano i
}

\section{Resumo}

O presente texto visa apresentar e descrever um programa de intervenção psicoeducativa dirigido a mulheres ciganas portuguesas, discutindo os seus resultados e as suas implicações do ponto de vista da análise das relações sociais de género no âmbito das comunidades ciganas. O programa de intervenção psicoeducativa que aqui se expõe, cujo objetivo central foi empoderar as participantes no sentido do desenvolvimento das suas competências e da promoção da sua participação comunitária, foi implementado, entre os meses de setembro e dezembro de 2015, junto de três grupos, abrangendo um total de 36 mulheres ciganas, residentes na zona norte do país. Os resultados da eficácia do programa, obtidos com recurso a uma metodologia qualitativa de pré e pós-teste, revelam a aquisição de conhecimentos e de competências no que respeita às questões da saúde, da educação e da igualdade de género.

Palavras-chave: comunidades ciganas; mulheres; género; empowerment.

\footnotetext{
* Centro Interdisciplinar de Estudos de Género (CIEG,ISCSP-ULisboa) Email: asneves@ismai.pt

**Email: ariana.pinto.correia@gmail.com

** Email: paula.allen.0977@gmail.com
} 


\begin{abstract}
Reflections on the implementation of a programme of psychoeducational intervention with Portuguese Roma women.

This paper aims to present and describe a programme of psychoeducational intervention with Portuguese Roma women, discussing its results and implications from a perspective of gender social relations in the Roma communities. This programme of psychoeducational intervention, aimed at empowering the participants and developing their skills and community participation, was implemented in three groups, reaching 36 Roma women, residents in the north of Portugal. The effectiveness of the programme, obtained through a qualitative methodology of pre- and post-testing, revealed the acquisition of knowledge and skills regarding health, education and gender equality issues.
\end{abstract}

Keywords: roma communities; women; gender; empowerment.

\begin{abstract}
Resumé
Réflexion sur la mise en ouvre d'un programme d'intervention psychoéducative avec des femmes Roms portugaises.

Le présent texte vise à présenter et à décrire un programme d'intervention psychoéducative destiné aux femmes Roms portugaises, discutant ses résultats et implications du point de vue de l'analyse des relations sociales de genre au sein des communautés roms. Ce programme d'intervention psychoéducative, dont l'objectif central était de donner aux participantes les moyens de développer leurs compétences et de promouvoir leur participation dans la communauté, a été mis en œuvre, de septembre à décembre 2015, auprès de trois groupes, couvrant au total 36 femmes Roms vivant dans le nord du pays. Les résultats sur l'efficacité du programme, obtenus au moyen d'une méthodologie qualitative avant test et après test, montrent l'acquisition de connaissances et de compétences concernant la santé, l'éducation et l'égalité des genres.
\end{abstract}

Mots-clés : communautés roms ; femmes ; genre ; empowerment.

\title{
Introdução
}

Estima-se que, em toda a Europa, existam cerca de seis milhões de ciganos/ as $^{1}$ (European Commission, 2015), dos quais 40 a 60 mil vivem em Portugal (ACIDI, 2013). Ao longo da História, as comunidades ciganas têm sido aquelas que, porventura, mais têm sido sujeitas à exclusão social. Subsistem sobre elas,

1 Os/As ciganos/as portugueses/as, não obstante a sua ascendência Rom, Sinti, Manouch e Calé, são conhecidos/as no país, quer pela população em geral, quer pelo meio académico, como ciganos/as (Casa-Nova, 2009). Por esse motivo, e porque esta é também a designação mais usada pelos/as próprios/as, optou-se neste texto por adotar os conceitos de ciganos/as e comunidades ciganas. Ambos, ao serem referenciados no plural, remetem para a heterogeneidade e pluralidade cultural dos diferentes grupos (Nicolau, 2010). 
ainda hoje, representações e práticas de discriminação que atentam contra os seus direitos fundamentais, restringindo o exercício de uma cidadania condigna (European Commission, 2014; FRA, 2012).

A ciganofobia generalizada, como uma forma específica de racismo e de fobia étnica promotora de processos de diferenciação e de hierarquização identitária (Bastos, 2007, 2012), tem ganho expressão em consequência do aumento do radicalismo e do extremismo europeus, fomentado a segregação étnico-cultural de crianças, mulheres e homens (European Commission, 2016, Loveland, 2016). Reconhecida esta tendência, a União Europeia formulou, em abril de 2011, um quadro europeu para as estratégias nacionais de integração das comunidades ciganas até 2020, com o objetivo de promover a coordenação de esforços entre os Estados Membros no sentido da diminuição do fosso entre estas e as comunidades não-ciganas no acesso à educação, ao emprego, à saúde e à habitação (Comissão Europeia, 2011).

Em Portugal, assim como no resto da Europa, os/as ciganos têm sido impedidos/as de se afirmar como cidadãos/ãs de pleno direito, sendo frequentemente arredados/as do espaço público e confinados/as a um estatuto de marginalização (e.g., Castro, 2010; Dias, Alves, Valente e Aires, 2006; Gomes, 2014; Silva, 2005; Silva, 2014; Mendes e Magano, 2013). Um estudo realizado pela Agência dos Direitos Fundamentais da União Europeia (FRA, 2012), junto de 11 Estados Membros, incluindo Portugal, revelou que a situação socioeconómica dos/as ciganos/as, nas áreas do emprego, da educação, da habitação e da saúde é dramática, sendo pior, em média, do que a situação dos/as não ciganos/ as.

Em 2013, e através da Resolução do Conselho de Ministros n. ${ }^{\circ}$ 25/2013, o governo português adotou a Estratégia Nacional para a Integração das Comunidades Ciganas (2013-2020), norteada por um eixo transversal e por eixos de intervenção sectoriais - Educação, Emprego e Formação e Saúde (ACIDI, 2013). As questões da igualdade de género perpassam toda a Estratégia Nacional, sendo contempladas não apenas como uma dimensão específica, mas também como uma prioridade em alguns dos eixos sectoriais.

Com efeito, as mulheres ciganas têm vindo a ser referenciadas, nos estudos nacionais e internacionais (e.g., Allen, 2012; Casa-Nova, 2006; Cortesão, Stoer, Casa-Nova e Tavares, 2005; Foldes e Covaci, 2012; Fonseca, 2009; Corsi et al., 2010; Magano, 2014; Mendes, 2010; Schneeweis, 2016, Vicente, 2009), como os elementos mais vulneráveis das suas comunidades, quer quando comparadas com os homens ciganos, quer quando comparadas com as mulheres das comunidades não-ciganas. Enfrentam, assim, uma dupla discriminação, a étnica e a de género, estando esta patente em domínios como a educação, a habitação, a saúde, o emprego, os benefícios sociais e o acesso a serviços financeiros (e.g., Corsi et al., 2010; Silva, 2005). 
De acordo com a Comissão Europeia (2006), as mulheres ciganas são confrontadas com desafios muito particulares. A cultura cigana prescreve às mulheres papéis familiares que as limitam em termos do seu envolvimento na vida política e pública; as mulheres ciganas têm riscos acrescidos no que toca à saúde, relacionados sobretudo com gravidezes precoces e múltiplas; foram, até recentemente e em alguns países, sujeitas a programas de esterilização forçada; têm más condições de habitação, maior sobrecarga de afazeres domésticos e menos oportunidades de integração em empregos locais; têm frequentemente baixas habilitações literárias, possuindo um elevado nível de iliteracia que se deve, em larga medida, ao abandono precoce da escola; são mais propensas à precariedade e ao desemprego e mais dependentes de subsídios sociais; sofrem mais processos de discriminação e são mais vítimas de diferentes formas de violência, nomeadamente de violência doméstica.

O Estudo Nacional sobre as Comunidades Ciganas, realizado em Portugal (Mendes, Magano e Candeias, 2014), evidenciou que, em relação aos papéis de género, continuam a verificar-se diferenças entre homens e mulheres, especialmente no que concerne ao contexto escolar, muito embora pareçam estar em curso algumas mudanças nas relações sociais de género, de um modo geral. $46.8 \%$ dos/as inquiridos/as concordam que as mulheres devem ter os mesmos direitos e tratamento que os homens, sendo que $32.1 \%$ não consideram que os meninos sejam mais importantes do que as meninas. Um número expressivo entende, contudo, que as mulheres de vergonha (p. 273) não devem frequentar determinados lugares na ausência dos maridos (41.9\%) e que são os homens quem devem decidir sobre os assuntos mais importantes da família $(34.8 \%)$.

Tais dados revelam haver uma aparente tensão entre posições mais conservadoras legitimadas pela cultura cigana sobre o papel das mulheres nas comunidades e posições mais consentâneas com uma perspetiva baseada na igualdade de género. É recomendado, pois, no estudo anteriormente referido, que se aposte na capacitação e empowerment das pessoas ciganas, dedicando-se uma maior atenção às mulheres.

O Projeto (In)Formar para a Igualdade e para a Cidadania, financiado pelo Fundo de Apoio à Estratégia Nacional para a Integração das Comunidades Ciganas (FAPE) e gerido pelo Alto Comissariado para as Migrações (ACM), no âmbito do qual este programa de intervenção psicoeducativa se insere, está alinhado com a recomendação explanada anteriormente, bem como com algumas das prioridades da Estratégia Nacional para a Integração das Comunidades Ciganas (ACIDI, 2013), nomeadamente a prioridade 5 - incentivar à participação das comunidades ciganas, enquanto exercício de cidadania -, e a prioridade 8 - enquadrar os valores familiares ciganos nos princípios e valores da sociedade portuguesa -. 
Descreve-se, em seguida, os objetivos e a estrutura do programa de intervenção psicoeducativa, caracterizando-se as participantes e discutindo-se os resultados alcançados e as suas implicações.

\section{0 Programa de Intervenção Psicoeducativa com mulheres ciganas portuguesas}

O programa de intervenção psicoeducativa com mulheres ciganas assenta na perspetiva do empowerment das participantes, através do desenvolvimento das suas competências e da promoção da sua participação comunitária. O empowerment é aqui entendido como um processo ou mecanismo através do qual as pessoas, organizações e comunidades assumem o controlo sobre as suas vidas (Rappaport, 1984). No que respeita às populações mais desfavorecidas, o empowerment traduz a aquisição de poder para lutar contra a opressão (Crondahl e Karlsson, 2015). No caso das mulheres, o empowerment pressupõe não apenas a igualdade de capacidades, de recursos e de oportunidades, mas a possibilidade de usá-la no sentido da tomada de decisão e da agência (Crowley, Genova e Sansonett, 2013).

São objetivos específicos do programa a) promover competências pessoais e sociais de autonomização; b) educar para a saúde; c) sensibilizar para a igualdade de género; d) prevenir a violência de género; e e) informar sobre os direitos.

O programa está organizado em 10 sessões $^{2}$ com a duração média de 1 h30m cada, sendo a sessão 0 e a sessão 9 de pré e pós-teste respetivamente. Nas restantes sessões são trabalhados, com recurso a atividades de psicoeducação, os seguintes módulos: 1) Estilos de vida e saúde alimentar (Sessão 1); Saúde Sexual e Reprodutiva (Sessões 2 e 3); Identidade (Sessões 4 e 5); Igualdade de Género (Sessão 6) e; Violência de Género (Sessão 7). A sessão 8 é destinada à consolidação das aprendizagens e à facilitação da despedida.

A seleção dos módulos, que foi feita em colaboração com as entidades parceiras do Projeto, procurou ir ao encontro de algumas das evidências do Estudo Nacional sobre as Comunidades Ciganas (Mendes, Magano e Candeias, 2014) o qual identificou, entre outros problemas, a existência de uma elevada taxa de pessoas com carências alimentares graves, doenças respiratórias e cardiovasculares, diabetes e colesterol, a parca utilização de métodos contracetivos, o insucesso e/ou abandono escolar precoce, a reduzida participação social e política e o conservadorismo relativamente às relações sociais de género.

2 O Grupo 3 apenas frequentou 5 sessões, a sessão 0 e as 4 seguintes. Tal facto deveu-se à doença terminal de um dos patriarcas da comunidade, a qual motivou o absentismo de um número elevado de participantes. 


\subsection{Caracterização das participantes}

Participaram deste programa de intervenção psicoeducativa 36 mulheres ciganas, 13 no Grupo 1, 15 no Grupo 2 e oito no Grupo 3. Residentes na zona norte do país, mais concretamente nos Distritos do Porto e de Aveiro, as participantes tinham idades compreendidas entre os 18 e os 60 anos (X=26). A média de idades do Grupo 1 era de 23 anos, do Grupo 2 de 30 anos e do Grupo 3 de 25 anos. Em todos os grupos o estado civil predominante era a união de facto, sendo a média do número de filhos/as nos Grupos 2 e 3 de dois e no Grupo 1 de um. No que respeita às habilitações literárias, no Grupo 1 as participantes possuíam, na generalidade, o $1 .^{\circ}$ Ciclo do Ensino Básico e nos Grupos 2 e 3 não tinham escolaridade. No Grupo 1 um grande número de mulheres era feirante, sendo que nos Grupos 2 e 3 se encontravam, na sua quase totalidade, desempregadas.

O Grupo 1 e o Grupo 3 residiam em complexos habitacionais e o Grupo 2 em acampamento.

Tabela 1

Caracterização sociodemográfica das participantes

\begin{tabular}{cccc} 
& Grupo 1 & Grupo 2 & Grupo 3 \\
\hline Média de idades & 23 & 30 & 25 \\
\hline Média do n. ${ }^{\circ}$ filhos/as & 1 & 2 & 2 \\
\hline Estado civil predominante & União de facto & União de facto & União de facto \\
\hline $\begin{array}{c}\text { Habilitações literárias } \\
\text { predominantes }\end{array}$ & $\begin{array}{c}1 .^{\circ} \text { Ciclo do } \\
\text { Ensino Básico }\end{array}$ & Sem escolaridade & Sem escolaridade \\
\hline Ocupação predominante & Feirantes & Desempregadas & Desempregadas \\
\hline Total de participantes & 13 & 15 & 8 \\
\hline
\end{tabular}

\subsection{Instrumentos de recolha de dados}

Por forma a caracterizar-se os grupos de mulheres ciganas foi criada uma ficha sócio-biográfica com informação genérica sobre as participantes. Foi entregue a cada uma delas um consentimento informado, o qual foi lido em voz alta antes de ser assinado ou anuído verbalmente (no caso das participantes sem escolaridade) pelas partes.

\subsection{Procedimentos de implementação e avaliação do Programa}

Com o intuito de maximizar a adesão das participantes e rentabilizar os resultados da implementação do programa de intervenção psicoeducativa, foram contactadas instituições que desenvolviam já trabalho de campo com as comunidades ciganas dos Distritos do Porto e de Aveiro e que, por conseguinte, tinham uma relação privilegiada com as populações alvo. Depois de 
partilhados os objetivos do programa, solicitou-se às equipas técnicas das instituições um levantamento das necessidades de intervenção, bem como a identificação das mulheres ciganas que mais poderiam vir a beneficiar da participação nos grupos. Foram identificadas como necessidades prioritárias de intervenção as áreas da saúde, especialmente da saúde sexual e reprodutiva, das doenças crónicas e dos hábitos alimentares, bem como as questões relacionadas com a construção do projeto de vida e da identidade (e.g., ser mulher, ser cigana, ser cidadã). Uma vez definidos os temas dos módulos, sempre em articulação com as instituições parceiras, estas procederam ao contacto direto com as mulheres ciganas a fim de se obter a sua autorização para a constituição dos grupos.

As sessões foram dinamizadas, entre os meses de setembro e de dezembro de 2015, por duas psicólogas, com base numa matriz psicoeducativa.

A implementação do programa foi sujeita a uma metodologia de avaliação da eficácia pré e pós-teste que, pelas características das participantes, se optou que fosse qualitativa. Embora na generalidade das intervenções desta natureza a avaliação da eficácia se faça através da aplicação de medidas estandardizadas, considerou-se ser mais adequado, tendo em conta as habilitações literárias das participantes, usar a técnica da vinheta, a qual permite a análise de imagens e/ou narrativas. Assim, as vinhetas são histórias sobre indivíduos ou situações que permitem recriar situações concretas quotidianas, apelando à discussão e à reflexão. As imagens, muito em particular, auxiliam na abordagem de temáticas consideradas sensíveis (e.g., vitimação, doença, desvio), sobretudo junto de grupos que são menos recetivos a materiais escritos estruturados (Hughes e Huby, 2004). Nas sessões 0 e 9 foram apresentadas quatro vinhetas (imagem, narrativa e guião de entrevista) criadas para o efeito pelo ilustrador Júlio Oliveira, com o objetivo de caracterizar as representações das mulheres ciganas acerca dos temas sobre os quais versa o programa - educação, saúde, alimentação e violência de género, - antes e depois da sua implementação. Depois de apresentada a imagem, era narrada para cada uma das vinhetas uma história sobre os temas em análise, seguindo-se um conjunto de questões previamente formuladas que visava facilitar a discussão. Quando autorizado pelas participantes (o Grupo 1 não autorizou) o processo de avaliação das vinhetas foi gravado em áudio, tendo sido as entrevistas transcritas e sujeitas a uma análise de conteúdo.

A vinheta 1 aborda as questões da educação explorando, entre outros aspetos, as representações sobre a relação das comunidades ciganas com a escola, muito em particular as diferenças de género no acesso à escolaridade e à vida profissional. 


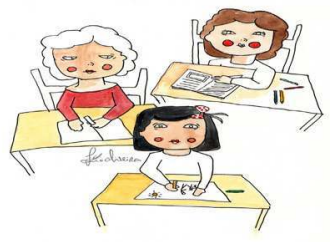

A vinheta 2, referente às questões da saúde, traz à discussão, entre outros, os temas do planeamento familiar, da gravidez e da maternidade/ paternidade. A narrativa gira em torno de um jovem casal heterossexual cujo filho nasceu recentemente.

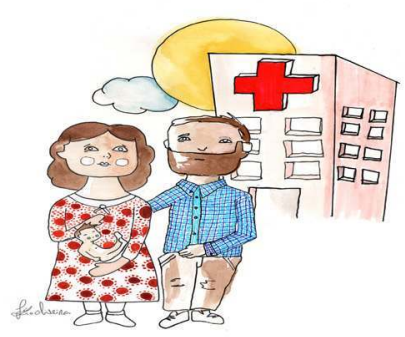

A vinheta 3, relacionada com as questões da alimentação, incide sobre os hábitos alimentares e os estilos de vida. É questionada, no âmbito do guião, a relação entre práticas alimentares de risco e o desenvolvimento de doenças associadas.

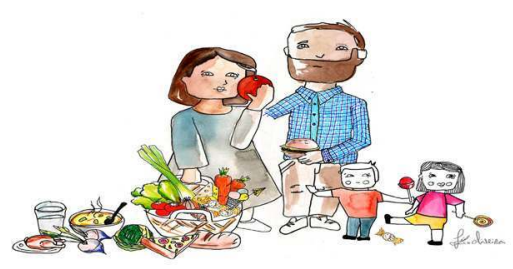


A vinheta 4 , sobre a violência de género, convida à reflexão sobre as causas e as consequências da violência contra as mulheres. A narrativa retrata a história de uma mulher cigana vítima de violência por parte do marido.

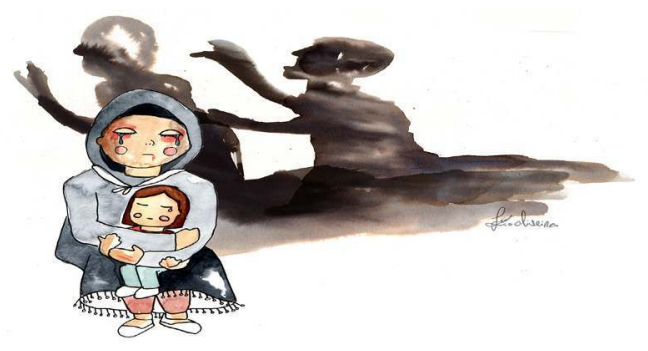

Todas as sessões foram avaliadas quanto ao nível de satisfação e aprendizagem das participantes dedicando-se cerca de 10 minutos no fim de cada uma delas a uma reflexão conjunta.

\subsection{Resultados}

Com vista a aferir a eficácia da implementação do programa de intervenção psicoeducativa foram comparados os resultados das respostas dadas às vinhetas na sessão 0 e na sessão 9 , pelos Grupos 1 e $2^{3}$, podendo concluir-se globalmente pelo aumento de conhecimentos por parte das participantes nos domínios que se expõem nesta secção. Para melhor se ilustrar os resultados serão apresentados alguns excertos das entrevistas. Foi usada, para cada um dos Grupos, a seguinte codificação: Grupo 1 [G1] e Grupo 2 [G2].

\section{Educação}

A discussão em torno da vinheta que retrata a área da educação foi uma das que gerou maior envolvimento por parte dos grupos. As participantes refletiram não só sobre os discursos e as práticas em torno dos percursos escolares das

3 Uma vez que o Grupo 3 não frequentou as 10 sessões previstas não foi possível proceder à avaliação pré e pós-teste neste caso. 
crianças ciganas, como sobre as relações entre as comunidades ciganas e a escola.

A escolarização das meninas, ao nível do $10^{\circ}$ e $2 .^{\circ}$ ciclo, foi considerada fundamental não tendo sido, no entanto, a continuidade da formação, após esses ciclos, avaliada como positiva por todas as mulheres ciganas. $\mathrm{Na}$ ótica da maioria das participantes a escolarização dos meninos até uma fase mais avançada é mais normativa do que a das meninas, por razões que se prendem com a própria organização da vida familiar e com os papéis atribuídos ao sexo feminino.

A escola tende a ser percebida, também pela grande maioria das participantes, como um espaço de tensões e de conflitos entre a cultura cigana e a cultura dominante. Relatos de segregação social e de discriminação das crianças ciganas reforçam a perceção de desproteção e de insegurança, especialmente em relação às meninas, a qual parece estar associada, a par de outros fatores, à realidade do abandono escolar precoce.

Após a implementação do programa verificou-se não só um aumento do reconhecimento da importância da educação para o desenvolvimento e a autonomia das meninas/mulheres ciganas, como também um reforço da sua motivação para a independência. Porém, a questão da manutenção das meninas na escola não é uma questão consensual entre as comunidades ciganas, espelhando-se essa controvérsia intra e intergrupos.

"As raparigas devem estudar até quando quiserem se quiserem ter um futuro melhor. (...) Os rapazes acho que devem estudar mais porque podem ter mais oportunidade, agora as raparigas? Que oportunidades? (...) aqui a única coisa que posso fazer é andar nas feiras! (...) Isto da educação já vem de geração em geração” [G1].

"Eu tenho 37 anos e ainda estou a estudar, no curso. Gostava que as minhas filhas tivessem uma vida melhor que a minha” [G2].

Ainda assim, todas parecem ter ficado mais despertas para as consequências do absentismo e do abandono escolar e para os seus impactos na integração profissional e social das mulheres ciganas. A conciliação entre o trabalho e a família começa a ser equacionável para estas mulheres, desde que com o devido apoio e anuência do agregado.

\section{Saúde}

Neste domínio a discussão centrou-se nos estilos de vida, nos comportamentos de prevenção da doença e de promoção da saúde e no planeamento familiar. 
Os ganhos salientaram-se particularmente no que se refere à saúde sexual e reprodutiva. As participantes conseguiram identificar um maior número de métodos contracetivos, depois da implementação do programa, mostrando-se mais cientes da importância do planeamento familiar não apenas para a saúde dos/as filhos/as, mas também para a sua própria saúde. Demonstraram também maior conhecimento quanto aos riscos associados à ausência de supervisão e acompanhamento médico, particularmente durante o período de gravidez e o pós-parto.

Estando duas sessões orientadas para o tema Saúde Sexual e Reprodutiva, foram trabalhados os aspetos relacionados com os direitos sexuais e reprodutivos, os quais estão, no caso concreto destas mulheres, muito vinculados à maternidade. Após a implementação do programa, a consciência face aos direitos das mulheres pareceu ter ficado substancialmente reforçada. Uma grande parte das mulheres verbalizou, contrariando uma posição inicial mais ou menos generalizada, que a decisão de engravidar deve ser do casal ou da mulher, insurgindo-se contra a tendência de ser a sogra (mãe do marido) a ditar a vida familiar do filho homem. A cedência a pressões externas foi, ainda assim, identificada como difícil de gerir, havendo a preocupação de não colidir com os princípios da Lei Cigana. Contudo, no Grupo 2, algumas mulheres, sobretudo as mais velhas, defenderam a posição dos sogros e a autoridade do marido nesta matéria. Além disso, quando parece haver desacordo no seio do casal quanto ao ter ou a não ter filhos/as é, por norma, a mulher que cede à obrigação natural da maternidade.

"Eu acho que é ela que deve decidir, o corpo é dela, ela é que carrega a criança 9 meses na barriga!” [G1].

"Deve ser o casal, mas os sogros também mandam (...) é o marido que manda” [G2].

\section{Alimentação}

O tema da alimentação foi um dos que gerou menos partilha no seio dos grupos. Estes foram unânimes em considerar que nem sempre os seus comportamentos são equilibrados e harmoniosos. Identificaram o consumo excessivo de sal e de açúcar como um dos aspetos mais negativos das suas rotinas alimentares, sendo o consumo excessivo de açúcar mais proeminente no caso das crianças e jovens (e.g., refrigerantes, doces). Na sessão de pós-teste, os Grupos 1 e 2 elencaram um maior número de doenças em consequência da adoção de estilos de vida menos saudáveis, reconhecendo os fatores de risco associados. Revelaram maior consciência sobre o caráter hereditário de algumas doenças, 
bem como admitiram a necessidade de efetuar exames e análises de rotina, recorrendo ao/à médico/a de família.

Não se evidenciaram mudanças concretas relativamente aos estilos de vida, embora se tivesse insistido na necessidade de praticar exercício físico.

\section{Violência de género}

Dentre os temas trabalhados, o tema da violência de género na intimidade foi aquele que suscitou mais resistências nos grupos. $\mathrm{Na}$ sessão de pré-teste foi notória a dificuldade em assumir posições sobre o assunto, estando as participantes na sessão de pós-teste mais disponíveis para falar e refletir sobre ele. Foi evidente o desconforto gerado aquando da apresentação, pela primeira vez, da vinheta que retratava o caso de uma mulher vítima de violência pelo marido. Destaca-se a evolução do Grupo 2 que passou de uma postura inicial de resignação face à violência ("no lugar dela não contava"), para um posicionamento de defesa da denúncia da situação (“deve pedir ajuda porque não tem culpa da situação e corre risco de vida”). Os agressores foram apelidados, pelo Grupo 1, de "loucos", "psicopatas", "maus pais" e "maus maridos”. Embora ambos os grupos tivessem reconhecido que as vítimas de violência na intimidade são vulneráveis, inclusivamente à prática de femicídio, a decisão da denúncia parece acarretar dilemas pessoais e culturais, dado que contraria a Lei Cigana.

"Por vergonha, ou por não ter o apoio da família, deve ter medo que a critiquem, porque vai ser uma vergonha para os pais ter uma filha separada (...) [G1].

"Têm medos que não acreditem, eles muitas vezes não são o que parecem (...), podem culpá-las (...), é a lei” [G2].

No âmbito das comunidades ciganas, e segundo a ótica da maioria das participantes, os casos de violência contra as mulheres devem ser tratados no contexto da família, sendo raras as vezes em que as vítimas reportam o crime às autoridades. Espera-se, assim, que seja a família das vítimas e a comunidade, de uma forma geral, a defendê-las dos agressores não estando, porém, salvaguardados os seus direitos em relação aos/às filhos/as. Segunda elas, a Lei Cigana não legitima nem toleram a violência contra as mulheres e as crianças. 


\section{Conclusões}

Depois de analisados os resultados da implementação do programa de intervenção psicoeducativa com mulheres ciganas conclui-se não apenas pela sua eficácia - no sentido do aumento dos conhecimentos das participantes face a alguns temas - mas também pela sua relevância social, uma vez que foram visíveis os seus efeitos na relação intragrupos e na participação comunitária. Não só as mulheres revelaram sentir-se mais confiantes e seguras das suas capacidades, como houve reflexos desse incremento da auto-estima na interação em grupo. Com efeito, as sessões serviram de plataforma para a aquisição de novas competências e recursos, alguns dos quais resultantes da iniciativa das próprias. Destaca-se, no Grupo 1, o exercício do direito à petição que se consubstanciou na reivindicação da alteração do vocábulo cigano no Dicionário de Língua Portuguesa. Confrontadas com o seu pendor pejorativo, as participantes quiseram não só criar a petição online como subscrevê-la, o que implicou que fossem criados, numa das sessões, emails para cada uma. Tal ação teve um impacto muito positivo na perceção de auto-eficácia do Grupo 1, num primeiro momento e, posteriormente, no Grupo 2, o que contribuiu para a coesão interna. Teve também um efeito muito positivo na perceção do potencial da participação comunitária. Até ao momento a petição conta com 384 assinaturas.

Os três grupos, embora geograficamente próximos, apresentaram-se como bastante heterogéneos. Tal evidência recentra a discussão sobre a diversidade das comunidades ciganas e, muito em particular, sobre as diferenças entre os diferentes grupos de mulheres ciganas. A tensão entre a preservação da tradição e a emancipação feminina, não obstante, esteve patente em todos os grupos, tendo sido mais saliente no Grupo 2, onde as mulheres estavam expostas a uma maior precariedade e iliteracia. O Grupo 1 - aquele que possuía habilitações literárias ao nível do $10^{\circ}$ Ciclo do Ensino Básico e se encontrava numa situação de emprego, ainda que instável - foi o que assumiu uma postura mais próxima da simetria de género. Tal foi mais evidente no que às questões da educação, da saúde sexual e reprodutiva e da violência de género diz respeito, tendo-se mostrado mais autónomas e independentes. As características do grupo em questão - alfabetizado, financeiramente mais empoderado e mais jovem -, aliadas à intervenção que nele tem vindo a ser levada a cabo por outras entidades, favoreceram os resultados por nós obtidos. Pelo contrário, as participantes do Grupo 2 foram mais resistentes, fruto da sua menor estimulação social e da sua situação de elevada vulnerabilidade social. Ainda assim, respondeu aos desafios da intervenção e esteve particularmente motivado nas dinâmicas propostas, tendo criado com as psicólogas uma relação de grande cumplicidade. Embora não tão significativos quanto os ganhos do Grupo 1, os ganhos do Grupo 2 foram sobretudo ao nível da informação e das competências de valorização pessoal. Apesar de ser o grupo menos jovem 
e o mais resistente à mudança, de um modo geral, foi aquele que demonstrou mais à vontade na abordagem da informação sobre os métodos contracetivos, permitindo que as jovens solteiras permanecessem na sessão alusiva a esse tema, o que não sucedeu no Grupo 1.

O Grupo 3, embora não tivesse concluído o programa por motivos relacionados com a doença e morte de um familiar próximo, foi evidenciando alguns ganhos pontuais no decurso da intervenção, nomeadamente no que concerne à aquisição de conhecimentos. De notar que, nesse período, uma das participantes saiu de casa no âmbito de um processo de violência de género na intimidade.

Considerando as temáticas que versam o programa, entendemos que a da educação e a da violência de género foram as que geraram menos consenso nas comunidades ciganas em análise. A escolaridade das meninas é reconhecida como fundamental até determinada idade, sendo percebida como pouco relevante e até contraproducente, por algumas das participantes, a partir da adolescência, altura em que devem começar a ser preparadas para constituir família. Recorde-se que em Portugal, 66\% das crianças ciganas abandonam a escola antes dos 16 anos (FRA, 2012). Destas, 53\% são meninas.

Muitas das mulheres ciganas relataram, a propósito da integração na escola, experiências de racismo e de discriminação, o que sustenta a argumentação de que a escola é um lugar de perigo para as crianças, especialmente para as meninas, que são naturalmente, segundo elas, mais frágeis e indefesas.

Grosso modo, a escolarização parece ser mais valorizada no caso dos rapazes do que das raparigas, havendo um estímulo ao investimento diferenciado em função do sexo, acompanhando aliás uma tendência que parece ser característica das comunidades ciganas em Portugal (Casa-Nova, 2006; Mendes, Magano e Candeias, 2014; Moreno, 2004) e na Europa (European Comission, 2006). Também o receio de consequências negativas funciona, não raras vezes, para as mulheres, como um fator inibidor da realização de aspirações sociais individuais e familiares (Casa-Nova, 2006), estando a família, quase sempre, acima de qualquer outro projeto de vida.

Apesar da pressão social para a conformidade, denota-se nas mulheres ciganas mais jovens uma motivação para a conciliação da vida familiar e profissional. Tal evidência é corroborada pela participação académica recente das comunidades ciganas portuguesas, sendo a presença das mulheres ciganas nas universidades um indicador da transformação social que tem vindo a ser operada no país (Baranyai e Kiss, 2016). Se é verdade que as mulheres ciganas parecem estar gradualmente a ocupar a esfera pública, é menos verdade que os homens estejam a chamar a si as responsabilidades da esfera privada. Afirmações como "Nunca um cigano vai lavar ou passar" [G1] foram comuns entre as participantes. 
$\mathrm{Na}$ realidade, e como discutido no Estudo Nacional sobre as Comunidades Ciganas (Mendes, Magano e Candeias, 2014), ainda que continuem a verificar-se diferenças entre homens e mulheres, o facto é que as relações sociais de género nas comunidades ciganas têm vindo a reconfigurar-se nos últimos anos.

A temática da violência de género na intimidade foi, nestes grupos, como aliás tende a ser noutros grupos de mulheres, a mais difícil de trabalhar. As mulheres ciganas resistem em falar ou posicionar-se face a situações de violência entendendo, à luz da sua cultura, tratar-se este de um problema do foro privado que, por essa razão, deve ser resolvido em família. Informadas sobre os seus direitos enquanto cidadãs, legitimaram a importância da denúncia e da procura de apoio não deixando, contudo, de frisar que o assunto deve ser gerido preferencialmente no seio das próprias comunidades. Esta forma de organização social, centrada na preservação da família e no receio da perda dos vínculos culturais, parece potenciar a manutenção da violência, embora o afastamento da vida cigana seja assumido por algumas vítimas como uma alternativa consciente e deliberada aos processos de vitimação de que são alvo (Magano e Mendes, 2014). O sentimento de desconfiança face aos serviços públicos (e.g., saúde, autoridades policiais) desencoraja, muitas vezes, a procura de apoio, tornando mais difícil a obtenção dos apoios que são devidos às vítimas de violência doméstica (Crowley, Genova e Sansonett, 2013). Por outro lado, os estudos de prevalência da violência de género na intimidade nas comunidades ciganas são escassos ou inexistentes, o que acentua o caráter tabu de uma realidade que as mesmas admitem existir, mas que está por documentar. Globalmente, a implementação deste programa de intervenção psicoeducativa foi bem sucedida, como comprovam os resultados do pré e pós-teste. A qualidade do trabalho em rede com as instituições parceiras, numa lógica de aprendizagem bidirecional, para a qual também contribuiu a horizontalidade das relações entre as pessoas, foi seguramente um dos elementos que favoreceu este sucesso.

Como todos os projetos desta natureza, este também apresenta algumas limitações. O facto de não ter sido possível aferir a eficácia dos resultados através de uma metodologia mais estruturada, recorrendo por exemplo a medidas de avaliação dos construtos abordados (e.g., empowerment) inviabiliza uma leitura mais informada dos dados obtidos. Igualmente a ausência quase total de referências na área da intervenção em grupo com comunidades ciganas e, por conseguinte, de estudos de eficácia, dificultou a construção e desenvolvimento do programa. Finalmente, o facto deste ser um Projeto financiado, i.e., com uma duração limitada no tempo, fez com que não houvesse uma perspetiva de continuidade da intervenção, a qual entendemos ser fundamental para garantir a sustentabilidade dos ganhos. 
Cremos, assim, ser imperativo apostar em ações que cimentem, a médio e a longo prazo, o empowerment das comunidades ciganas, não apenas junto das mulheres, mas também dos homens. A eficácia da construção de um projeto de igualdade dependerá, como acontece aliás noutras comunidades, da capacidade de envolver todos os intervenientes na mudança.

\section{Referências}

ACIDI (2013), Estratégia Nacional para a Integração das Comunidades Ciganas. Lisboa: ACIDI [Online], disponível em http://www.acm.gov.pt/documents/10181/52642/enicc_ACM. pdf/42f8ef57-8cd7-4118-9170-9fcd9bc53ec2 [consultado em: 12.07.16].

ALLEN, Paula (2012), “(Des)Encantos de ser mulher cigana: representações da sua sexualidade”, Saúde Reprodutiva, Sexualidade e Sociedade, 1, 45-63.

BARANYAI, Berill, KISS, Nóra (2016), Opré Chavalé - Quebrar as barreiras que separam as comunidades ciganas do ensino superior, Lisboa: Plataforma Portuguesa para os Direitos das Mulheres. Disponível em http://plataformamulheres.org.pt/wp-content/ficheiros/2016/07/ Opre-Chavale-publicacao.pdf [consultado em: 22.07.16].

BASTOS, José Gabriel Pereira (2007), Que futuro tem Portugal para os portugueses ciganos?, Lisboa, CEME.

BASTOS, José Gabriel Pereira (Org., 2012), Portugueses ciganos e ciganofobia em Portugal, Lisboa, Colibri.

CASA-NOVA, Maria José (2006), A relação dos ciganos com a escola pública: contributos para a compreensão sociológica de um problema complexo e multidimensional. Interações, 2, 155-182.

CASA-NOVA, Maria José (2009), Etnografia e Produção de Conhecimento. Reflexões críticas a partir de uma investigação com ciganos portugueses, Lisboa, ACIDI.

CASTRO, Alexandra (2010), "Ciganos e desigualdades sociais: contributos para a inflexão de políticas públicas de cariz universalista”, Forum Sociológico, 20, pp. 11-19.

COMISSÃO EUROPEIA (2011), Comunicação da Comissão ao Parlamento Europeu, ao Conselho, ao Comité Económico e Social Europeu e ao Comité das Regiões. Um quadro europeu para as estratégias nacionais de integração dos ciganos até 2020. [Online], disponível em http://eur-lex.europa.eu/legal-content/PT/TXT/PDF/?uri=CELEX:52011DC0173\&fr om=EN [consultado em: 12.07.16].

CORSI, Marcella, CREPALDI, Chiara, LODOVICI, Manuela Samek, BOCCAGNI, Paolo e VASILESCU, Cristina (2010), Ethnic minority and Roma women in Europe A case for gender equality? Luxembourg: European Comission. [Online], disponível em http://rownosc.info/ media/uploads/ethnic_minority_and_roma_women.pdf [consultado em: 12.07.16].

CORTESÃO, Luíza, STOER, Stephen, CASA-NOVA, Maria José, TRINDADE, Rui (2005), Pontes para outras viagens. Escola e comunidade ciganas: representações recíprocas, Lisboa, ACIME.

CRONDAHL, Kristine e KARLSSON, Leena Eklund (2015), "Roma Empowerment and Social Inclusion Through Work-Integrated Learning”, SAGE Open, 5(1), 1-10. doi: 10.1177/2158244015572275

CROWLEY, Niall, GENOVA, Angela e SANSONETT, Silvia (2013), Empowerment of Roma Women within the European Framework of National Roma Inclusion Strategies, Brussels, European Union [Online], disponível em http://www.europarl.europa.eu/RegData/ 
etudes/etudes/join/2013/493019/IPOL-FEMM_ET(2013)493019_EN.pdf [consultado em: 26.08.16].

DIAS, Eduardo Costa, ALVES, Isabel, VALENTE, Nuno, AIRES, Sérgio (2006), Comunidades Ciganas. Representações e dinâmicas de exclusão/integração, Lisboa; ACIME.

EUROPEAN COMISSION (2006), Gender inequalities in the risks of poverty and social exclusion for disadvantaged groups in thirty European countries, Brussels, European Commission.

EUROPEAN COMISSION (2014), Report on the implementation of the EU framework for National Roma Integration Strategies, European Commission, Directorate-General for Justice.

EUROPEAN COMISSION (2015), Special Eurobarometer 437. "Discrimination in the EU in 2015", European Union.

EUROPEAN COMISSION (2016), "Effective Roma integration measures in the Member States 2016", Commission to the European Parliament, the Council, the European Economic and Social Committee and the Committee of the Regions. [Online], disponível em http://ec.europa. eu/justice/discrimination/files/roma-report-2016_en.pdf [consultado em: 14.07.16].

FONSECA, Laura (2009), Justiça social e educação: Vozes, silêncios e ruídos na educação escolar de raparigas ciganas e payas, Porto, Afrontamento.

FOLDES, Maria Eva e COVACI Alina (2012), "Research on Roma health and access to healthcare: state of the art and future challenges", International Journal of Public Health, 57(1), 37-39.

FRA (2012), The situation of Roma in 11 EU Member States [Online], Disponível em http://fra. europa.eu/sites/default/files/fra_uploads/2099-FRA-2012-Roma-at-a-glance_EN.pdf [consultado em: 25.08.16].

GOMES, Sílvia (2014), Caminhos para a prisão. Uma análise do fenómeno da criminalidade associada a grupos estrangeiros e étnicos em Portugal, Vila Nova de Famalicão, Húmus.

HUGHES, Rhidian e HUBY, Meg (2004), "The construction and interpretation of vignettes in social research”, Social Work \& Social Sciences Review, 11(1), 36-51.

LOVELAND, Matthew (2016), "The Gypsy Threat Narrative Explaining Anti-Roma Attitudes in the European Union”, Human and Society, 40(3), 329-352. doi: 10.1177/0160597615601715

MAGANO, Olga (2014), Tracejar vidas normais. Estudo qualitativo sobre a integração social de indivíduos de origem cigana na sociedade portuguesa, Lisboa, Mundos Sociais.

MAGANO, Olga e MENDES, Maria Manuela Ferreira (2014), “Mulheres ciganas na sociedade portuguesa: tracejando percursos de vida singulares e plurais”, Revista Sures [Online], 3, Disponível em https://revistas.unila.edu.br/index.php/sures/article/view/144/146 [consultado em: 25.08.16].

MENDES, Maria Manuela Ferreira (2010), Representações face à Discriminação. Ciganos e Imigrantes Russos e Ucranianos na Área Metropolitana de Lisboa, Lisboa, Imprensa de Ciências Sociais.

MENDES, Maria Manuela Ferreira e MAGANO, Olga (Orgs, 2013), Ciganos Portugueses. Olhares Plurais e Novos Desafios numa Sociedade em Transição, Lisboa, Mundos Sociais.

MENDES, Maria Manuela Ferreira, MAGANO, Olga e CANDEIAS, Pedro (2014), Estudo Nacional sobre as Comunidades Ciganas, Lisboa, ACM.

MORENO, Filomena Morais (2004), Etnia Cigana: Relação Homem-Mulher, Vila Nova de Gaia, Editorial 100.

NICOLAU, Lurdes Fernandes (2013), “A população cigana do Nordeste Transmontano”, in Maria Manuela Mendes, Olga Magano (orgs.), Ciganos Portugueses: Olhares Plurais e Novos Desafios Numa Sociedade em Transição, Lisboa, Mundos Sociais, pp. 207-222.

RAPPORT, Julian (1984), "Studies in empowerment: introduction to issues", Prevention in Human Services, 3 (2-3), 1-7. 
Resolução do Conselho de Ministros n. ${ }^{\circ}$ 25/2013 [Online], disponível em http://ec.europa.eu/ justice/discrimination/files/roma_portugal_strategy_pt.pdf [consultado em: 12.07.16].

SCHNEEWEIS, Adina (2016), "Ethnic minority and Roma women in Europe A case for gender equality?”, Journal ofCommunication Inquiry, 40(1), 88-105.doi:10.1177/0196859915606975

SILVA, Carlos Silva (Coord., 2014), Sina Social Cigana. História, comunidades, representações e instituições, Lisboa, Colibri.

SILVA, Luísa Ferreira (2005), Saúde-doença é questão de cultura: atitudes e comportamentos de saúde materna nas mulheres ciganas em Portugal, Lisboa, ACIME.

VICENTE, Maria José (2009), As comunidades ciganas e a saúde: um primeiro retrato nacional, Porto, Rede Europeia Anti-Pobreza. 